\title{
Impact of Transactional Analysis Psychotherapy Training on Self Awareness and Ability for Contact
}

\author{
(c) 2011 Biljana van Rijn, Ciara Wild, Heather Fowlie, Charlotte Sills, \\ Servaas van Beekum
}

\begin{abstract}
This research was a small scale quantitative study involving students undergoing Relational Transactional Analysis psychotherapy training at Metanoia Institute in London in the UK between September 2007 and July 2008. The researchers aimed to evaluate the impact of the training on students' psychological health, using the 'Autonomy Questionnaire' (Beekum \& Krijgsman, 2000). This allowed measurement of developments in students' self awareness and ability for contact with others during their second year of training (first year of clinical practice) compared to students in their 4th and final year. The scope of the study and the findings are exploratory. The research raises questions for further research in the areas of psychotherapy training and supervision.
\end{abstract}

\section{Key words}

Relational transactional analysis, self awareness, ability for contact, Autonomy Questionnaire, psychotherapy training

\section{Introduction: The importance of self awareness and ability for contact in \\ Relational clinical training}

The Relational Transactional Analysis perspective is "characterised by the development of affective, cocreated, conscious, non-conscious and unconscious relational interactions as a primary means of growth and change" (IARTA 2010). This interpersonal approach emphasises the importance of the therapist's ability for self awareness and self reflection as well as a capacity for developing a therapeutic relationship.

These aims of psychotherapy training are well supported by both clinical and research literature, particularly the field of common factors research and research on therapist variables. In their comparative study of Cognitive Behavioural and Psychodynamic/ Interpersonal psychotherapists (Goldfried et al 1997) show that Interpersonal and Psychodynamic psychotherapists focus more on insight and interpretation in their work, which demands a level of self awareness and the awareness of the process within the therapeutic relationship. This suggests the importance of developing personal awareness during training, particularly within the relational therapeutic traditions. However, the relevance of relational factors is not limited to interpersonal psychotherapies and Asay \& Lambert (1999) estimate that they account for around $30 \%$ of the variance in outcomes in all approaches, twice as much as technique.

Research studies also suggest a wide variation in effectiveness between individual therapists, which takes precedence over theoretical orientations and technique (Luborsky at al, 1985). A strong therapeutic relationship, in which the client feels understood and accepted, emerges as one of the 'common factors' of effective psychotherapy in a number of meta-analytic studies (Luborsky et al, 1975); (Lambert \& Bergin, 1994); (Smith \& Glass, 1977); (Wampold, 2001). Within that the working alliance, defined by Bordin (1979) as a collaborative relationship with three main components of goals, tasks and bonds, emerges as a consistent predictor of outcome (Horvarth \& Bedi, 2002); (Wampold, 2001).

However, these studies do not show how the roles of the therapist and the client account for differences in the therapeutic alliance and the outcomes. Historically clinical literature tended to focus on the role of the client in this process, even though more recent relational approaches analyse the complementary roles of the therapist and the client. Looking at the role of the therapist, Baldwin et al (2007) investigated different aspects of the working alliance in relation to 
psychotherapy outcomes and found that therapists who, on average, formed stronger alliances had more positive outcomes, even when they worked with clients who varied in their capacity to form a therapeutic alliance. This study has particular implications for psychotherapy training and suggests that ability to form a working alliance with clients could be seen as a significant training outcome for clinicians.

Further studies (cited in Cooper, 2008) confirm the importance of other relational factors such as empathy, positive regard and working alliance (Krupnick et al. 1996; Bohart and Tallman 1991) and their consistent impact across a variety of client groups.

An area of research of particular interest to Relational Transactional Analysts relates to the role of unconscious communication in the therapeutic process. It focuses on therapists' countertransference and attachment styles. Gelso \& Hayes (2002) in their review of research into the impact and management of countertransference suggest that therapists who are considered to have more 'integrated personalities' tend to have fewer countertransferential reactions, as did therapists who had high awareness of their feelings.

They concluded that the management of countertransferential responses was helpful to the therapeutic process and the therapists' self awareness and understanding as well as their own psychological health and 'self integration' were particularly important in this process. Clinical supervision and personal therapy were seen as important arenas for this development. In Transactional Analysis psychotherapy the analysis of therapists countertransference is relevant in the process of dealing with games (Berne, 1964) particularly from a constructivist, relational perspective (Hine, 1990), (Allen \& Allen, 1997), which emphasises the complementary and bilateral nature of psychological games.

Therapists' self awareness and integration are important in the area of attachment, because attachment patterns contain both conscious and unconscious material and are likely to influence the therapeutic relationship (Gelso \& Hayes, 2002; Tyrrell at al, 1999).

In Transactional Analysis, awareness has been linked to the concept of autonomy (Berne, 1964, 1966). Abilities for spontaneity, awareness and intimacy have been seen as aspects of psychological health contained within the human aspirations for autonomy. Research by van Beekum and Krijgsman (2000) challenged this notion and identified two distinct components of autonomy: self awareness and ability for contact. This research uses their definitions of autonomy to investigate whether psychotherapy training leads to an increase in self awareness and ability for contact.

\section{Training programme}

The TA Psychotherapy programme at Metanoia Institute takes place over four year-long modules, parttime. The course structure is graduated to increase in depth and challenge as the student progresses through its stages. These years of formal study are followed by a period of carefully supervised practice, as well as written and viva examinations. Woven throughout and between the modules are a variety of requirements for group and private study, practice, supervision, therapy and personal development, as well as written assignments.

The four years include theory, which is primarily transactional analysis but also other perspectives, relevant research and the integration of theory into clinical practice. Students are supported to develop as competent reflexive practitioners who can address professional/ethical issues and integrate their training, personal therapy, clinical and supervision experiences to develop their own personal style as TA practitioners. In particular they are supported to develop their abilities to use the therapeutic relationship as the central vehicle to assist clients in understanding and addressing their difficulties.

This emphasis upon the structured use of the therapeutic relationship requires students to reflect upon what factors make a relationship therapeutic, to learn and practise the skills involved in making and maintaining this relationship and to develop their ability to use their own experience and reflexivity in the service of the work. It involves the education of the person in self-awareness and self-reflection as well as training in a specific philosophical and theoretical approach.

This focus on the therapeutic relationship begins from the start of training but takes on a particular emphasis in the second year when students begin to see clients. In this year the training uses principles of action research as a basis for training (van Rijn et al., 2008); formal teaching is closely linked to the questions arising for students as they engage with and reflect on their practice.

To assist with this process, students undertake a reflective inquiry into their practice, with the support of their primary tutors and training supervisors. Training supervisors provided group supervision once a month, in an allocated section of the course. They are familiar with students individually, as well as the training programme. They supervise the same groups throughout the training year. Common reflective inquiries at this stage are "How does my 'Please Others' Driver get in the way of me being an effective practitioner?" or "What effect does my fear of conflict have on my interventions with clients"? Students engage with their inquiry in their practice and then reflect on it, primarily with their training supervisor, as a means of drawing out the learning experiences and 
findings from it. The overall aim of this inquiry is to assist the student to become more aware of the ways in which they potentially lose contact (and effectiveness) in relationship with their clients and to hopefully develop their ability to work through this.

\section{Methodology}

The overarching methodology for the project was based on action science (Argyris et al, 1987). Philosophically, this methodology is based on constructivist sensibilities and looks at research as a process which creates and shares knowledge within (organisational) systems. That means that all the participants are co-researchers, who share the process and the knowledge within the system.

The aim is to engage in cycles of inquiry using reflection, observation, implementation and evaluation, using quantitative, qualitative or mixed methods. The study is based in a 'real world' setting, which means that the number of participants is small and the sample is not randomised.

The fact that this is a naturalistic study with a small sample limits the generalisability of the evaluation. The study uses student questionnaires based on self report and therefore gives a view of subjective experience. As in all action research, this study aims to give insight, evaluate a lived organisational experience and ask questions. The scope of this paper is to present the quantitative analysis of this project.

\section{Methods}

The research team decided to use an evaluation method based on the transactional analysis concept of psychological health to evaluate the training programme. The Autonomy Questionnaire (van Beekum and Krijgsman, 2000) is a research based measure developed to evaluate the impact of transactional analysis supervision and coaching training on the psychological health of the participants. The questionnaire contained statements representing polarities related to two categories: self awareness (category $A$, 10 statements) and contact with others (category B, 9 statements).

Three groups of participants were involved in the evaluation: students in their second year of training, their training supervisors and students in their 4th year of training.

The 2 nd year students had training supervisors on site who were familiar with the training programme and employed by the Institute. Students and their supervisors were both asked to complete the Autonomy Questionnaire at the beginning and the end of their year. There were 19 students and 3 supervisors. They used the questionnaires to aid their professional and personal development and engage in their reflective inquiry during the year.

The research questionnaire was introduced to the 2 nd year group on the first weekend of the course, initially as a means of opening up a discussion on what they believed to be the qualities of an effective therapist. As a result of this discussion students were asked to reflect upon those qualities that they felt they comfortably owned and those that they struggled with. From this they developed their initial reflective inquiry question. They also filled out the research questionnaires at this point, which were then put in a sealed envelope and handed to the research team.

At the end of the second year, each student and their primary supervisor independently filled out the same questionnaire again; as before these were placed in a sealed envelope and handed to the research team.

Sixteen students on the fourth year of training also filled out the research questionnaire on their first and last weekends. Their supervisors were not involved, as they had supervision in private practice settings. By this year the emphasis on the therapeutic relationship has moved on from a more cognitive focus (2nd year) through a concentration on unconscious communication (3rd year) to one in the fourth year where the student is assisted to identify their own personal style of making and maintaining contact within the therapeutic relationship. Inquiry questions at this stage commonly involve noticing the impact of interventions on clients, exploring subtle countertransference responses and experimenting with different ways of engaging with clients and what they bring. Discoveries and hypotheses then form the basis of another cycle of inquiry into practice.

The Head of Clinical Services, who was the project leader, and the independent researcher, who conducted the statistical analysis, were not a part of training and therefore held a higher degree of separation from the project within the organisational system.

\section{Ethical Issues}

All participants were given written information about the project and a choice in taking part. They all signed a written consent form.

The action research principles used within the project ensured that issues of transparency were adhered to. Students were engaged in theirs' and their supervisors' evaluations and encouraged to discuss it in supervision session. However, questionnaires passed to the researcher were anonymous. The only identifying data was their year of training, because this was pertinent to the analysis. 


\section{Statistical Analysis and Outcomes}

Changes in categories of psychological health during training

Descriptive statistics were used to analyse the outcomes, which indicated a reduction in group means from pre training to post training reporting. This suggests that more students were marking lower numbers on the scale which represent increased levels of autonomy on both categories (self awareness $(A)$ and contact with others (B). The standard deviation also shows a reduction in the dispersion of scores from the pre to post measure, suggesting a greater consensus between the students and increased psychological health on both categories. This indicates that there was less difference between individual students at the end of training than at the beginning and suggests the impact of the training programme on the outcomes.

Initially each item on the scale was compared pre and post the training year, using a related t-test to investigate differences. It was found that items $6,9,10$, 18, 19 and the Total score were significantly different from pre to post $(P<0.05)$. These items related to both scales and could be investigated further in the future uses of the measure (Table 1).

\section{Supervisors' evaluation}

Recognising the limitations of the self report questionnaire, the study was widened to supervisors of students in the second year of training. Descriptive statistics showed that the average supervisor's scores of students were higher than the student's scores after training, suggesting that supervisors were recording lower levels of autonomy than students. This is supported by higher maximum and minimum scores recorded by the supervisors than by the students. Again using a related t-test, there are significant differences between the supervisors' and students' scores on items 1, 2, 9, 17 and the Total $(P<0.05)$. This suggests that supervisors did not record as high an increase in autonomy after the training year as did the students.

Interestingly, the significant differences between supervisors' ratings of students and students selfratings were found in the category of 'self awareness' items, not the 'contact with others' items. Significant differences at $\mathrm{P}<0.05$ were recorded between the students' A subscale on the post measure and the supervisors' A subscale and also the students' B subscale on the post measure and the supervisors' B subscale. These scores suggest that the self-reported increase

\section{Table 1: The Percentage change recorded by students between pre and post measures of self awareness}

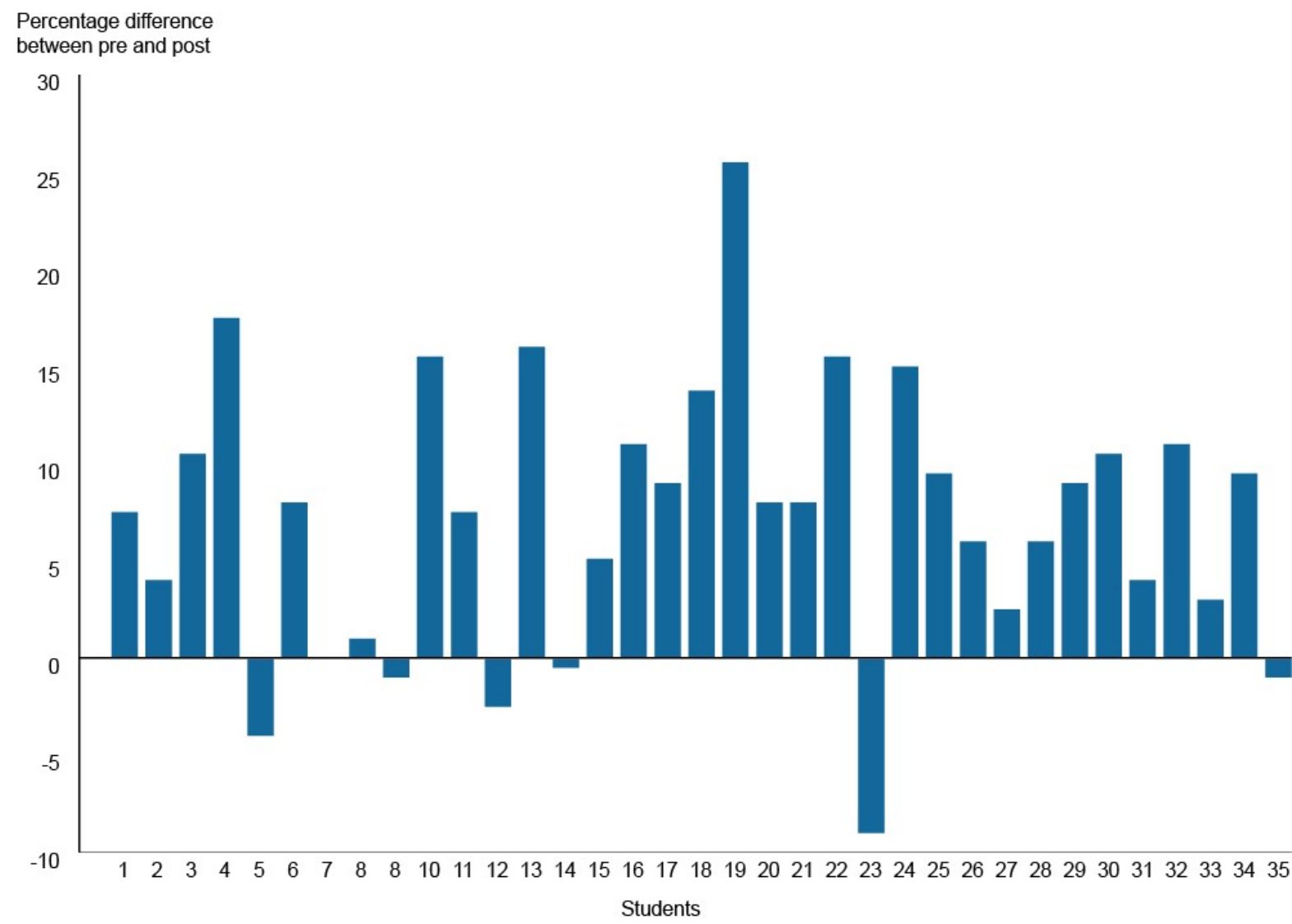


in self-awareness of the students is not reflected by the supervisor. The supervisors' total score and the students' total score on the post-training measure differ significantly.

\section{Comparison of Categories and Groups}

To measure the subscales within the Autonomy Questionnaire (A- self awareness; B- contact with others) a related t-test was employed (Table 2). The results showed that there were significant differences between subscales $A$ and $B$ on the pre measure, the post measure and the supervisor's measure $(P<0.05)$. This suggests that both groups increased their autonomy scores, both in the area of self awareness and contact with others, even though supervisors rated the changes differently to students.

An independent t-test was employed to investigate whether there was a significant difference between student's scores in their second year of training and those in their fourth year of training (Table 3). No significant difference was found between year two and year four of training for either the pre or post measure even though the Table 5 graph shows that year four have lower scores on average and therefore report a higher level of psychological health than year two. This is also true for the subscales total scores, where students in year two are reported to have higher scores (lower reported self-awareness) than students in year four however this difference is not significant.

Table 3 illustrates that there is a significant difference (change score) between the total scores for Pre Selfawareness and Contact and Post Self-awareness and Contact.

Table 4 shows that there is a significant difference between the groups for Contact change scores (the difference in pre and post only. Table 5 illustrates clearly that there is a greater change in Year 2 than Year 4 for Contact categories.

\begin{tabular}{|c|c|c|c|c|c|c|c|c|c|}
\hline & & \multicolumn{5}{|c|}{ Paired Differences } & \multirow[b]{3}{*}{$\mathbf{t}$} & \multirow[b]{3}{*}{ df } & \multirow[b]{3}{*}{$\begin{array}{l}\text { Sig. } \\
\text { (2Tailed) }\end{array}$} \\
\hline & & \multirow[b]{2}{*}{ Mean } & \multirow[b]{2}{*}{$\begin{array}{l}\text { Std. } \\
\text { Deviation }\end{array}$} & \multirow[b]{2}{*}{$\begin{array}{l}\text { Std. Error } \\
\text { Mean }\end{array}$} & \multicolumn{2}{|c|}{$\begin{array}{l}95 \% \text { Confidence } \\
\text { Interval of the } \\
\text { Difference }\end{array}$} & & & \\
\hline & & & & & Lower & Upper & & & \\
\hline Pair 1 & $\begin{array}{l}\text { PostATotal - } \\
\text { SupATotal }\end{array}$ & -6.526 & 5.471 & 1.255 & -9.163 & -3.889 & -5.200 & 18 & .000 \\
\hline Pair 2 & $\begin{array}{l}\text { PostBTotal - } \\
\text { SupBTotal }\end{array}$ & -3.789 & 4.662 & 1.069 & -6.036 & -1.543 & -3.543 & 18 & .002 \\
\hline Pair 3 & $\begin{array}{l}\text { PostTotal - } \\
\text { SupTotal }\end{array}$ & -10.316 & 9.534 & 2.187 & -14.911 & -5.721 & -4.716 & 18 & .000 \\
\hline
\end{tabular}

Table 3: Paired Samples Test

\begin{tabular}{|c|c|c|c|c|c|c|c|c|c|}
\hline & & \multicolumn{5}{|c|}{ Paired Differences } & \multirow[b]{3}{*}{$\mathbf{t}$} & \multirow[b]{3}{*}{ df } & \multirow[b]{3}{*}{$\begin{array}{l}\text { Sig. } \\
\text { (2Tailed) }\end{array}$} \\
\hline & & \multirow[b]{2}{*}{ Mean } & \multirow{3}{*}{$\begin{array}{l}\begin{array}{l}\text { Std. } \\
\text { Deviation }\end{array} \\
4.788\end{array}$} & \multirow{3}{*}{$\begin{array}{l}\begin{array}{l}\text { Std. Error } \\
\text { Mean }\end{array} \\
.809\end{array}$} & \multicolumn{2}{|c|}{$\begin{array}{l}95 \% \text { Confidence } \\
\text { Interval of the } \\
\text { Difference }\end{array}$} & & & \\
\hline & & & & & Lower & Upper & & & \\
\hline Pair 1 & $\begin{array}{l}\text { PreATotal - } \\
\text { PostATotal }\end{array}$ & 4.686 & & & 3.041 & 6.331 & 5.789 & 34 & .000 \\
\hline Pair 2 & $\begin{array}{l}\text { PreBTotal - } \\
\text { PostBTotal }\end{array}$ & 3.486 & 4.488 & .759 & 1.944 & 5.027 & 4.595 & 34 & .000 \\
\hline
\end{tabular}




\begin{tabular}{|c|c|c|c|c|c|c|c|c|}
\hline & & \multicolumn{2}{|c|}{$\begin{array}{l}\text { Levene's Test for } \\
\text { Equality of Variances }\end{array}$} & \multicolumn{5}{|c|}{ t-test for Equality of Means } \\
\hline & & $\mathbf{F}$ & Sig. & $\mathbf{T}$ & df & $\begin{array}{l}\text { Sig. } \\
\text { (2 Tailed) }\end{array}$ & $\begin{array}{l}\text { Mean } \\
\text { Difference }\end{array}$ & $\begin{array}{l}\text { Std. Error } \\
\text { Difference }\end{array}$ \\
\hline \multirow[t]{2}{*}{$\begin{array}{l}\text { DiffPre } \\
\text { Post }\end{array}$} & $\begin{array}{l}\text { Equal variances } \\
\text { assumed }\end{array}$ & 1.505 & .229 & .324 & 33 & .748 & .891 & 2.753 \\
\hline & $\begin{array}{l}\text { Equal variances } \\
\text { not assumed }\end{array}$ & & & .331 & 32.769 & .743 & .891 & 2.691 \\
\hline \multirow[t]{2}{*}{$\begin{array}{l}\text { DiffPre } \\
\text { PostA }\end{array}$} & $\begin{array}{l}\text { Equal variances } \\
\text { assumed }\end{array}$ & .024 & .877 & -.002 & 33 & .998 & -.003 & 1.649 \\
\hline & $\begin{array}{l}\text { Equal variances } \\
\text { not assumed }\end{array}$ & & & -.002 & 29.397 & .998 & -.003 & 1.675 \\
\hline \multirow[t]{2}{*}{$\begin{array}{l}\text { DiffPre } \\
\text { PostB }\end{array}$} & $\begin{array}{l}\text { Equal variances } \\
\text { assumed }\end{array}$ & 10.292 & .003 & .582 & 33 & .565 & .895 & 1.538 \\
\hline & $\begin{array}{l}\text { Equal variances } \\
\text { not assumed }\end{array}$ & & & .612 & 28.200 & .546 & .895 & 1.463 \\
\hline
\end{tabular}

Table 5:

\section{Graph illustrating the diference in change scores for the Contact Subscale}

Mean DiffPrePostB

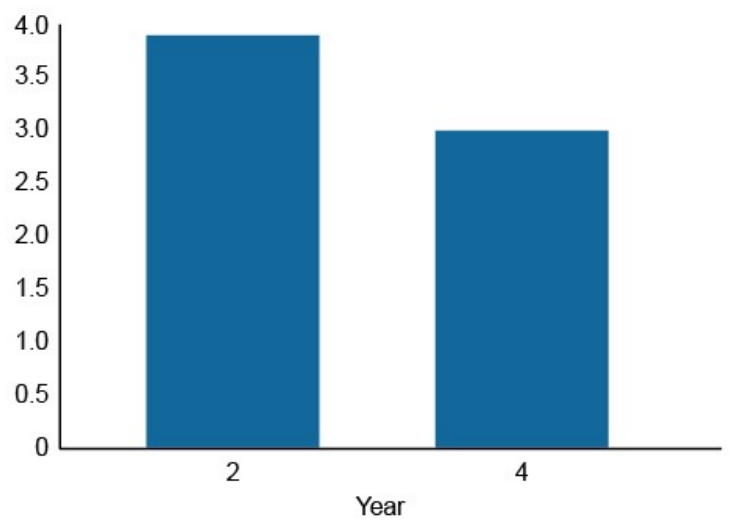

The association between the change in self awareness and clinical effect could not to be investigated as there were not sufficient data to do so. However further investigation on why there were significant differences on some of the items may have interesting connotations for further test development and for comparison to selfawareness theory and literature. Furthermore, investigation of the reasons behind supervisors' lower rating of students' self awareness could generate some interesting themes for training and for reflective practice.

\section{Discussion}

The outcomes of this research suggest that students' autonomy in the areas of self awareness and ability for contact, as measured by the 'Autonomy Questionnaire'

\section{Comparision between year 2 and year 4 on Pre and Post training measures}

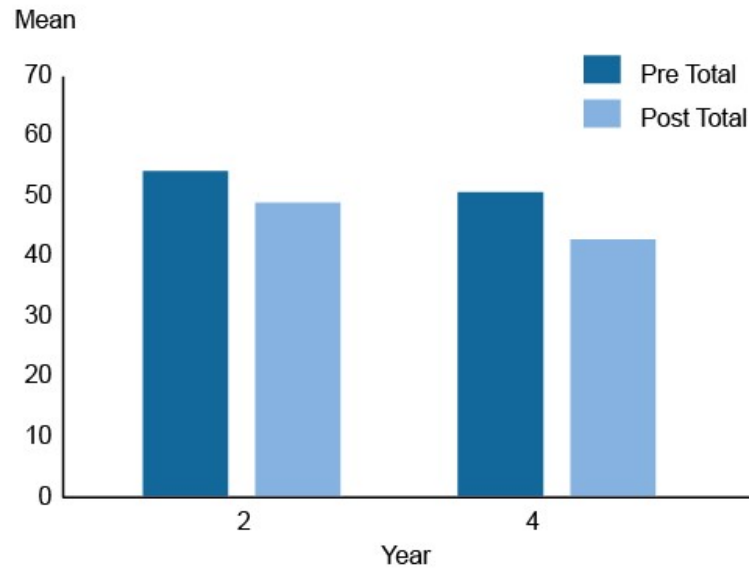

(Beekum \& Krijgsman, 2000) develops whilst they are being trained in the Transactional Analysis Relational approach in psychotherapy training. This suggests that the training meets its objective in developing students' capacity to engage in relationships with a corresponding impact on therapeutic practice. However, there is no data related to students' clinical practice at this time and this highlights an important area of further research.

These findings are limited by the size of the research group, the measure and the methodology and raise a number of interesting questions and opportunities for further research. One of these questions relates to the use of a self report measure. Differences between students and their supervisors in the evaluation of self 
awareness in the second year of training raise interesting questions. We could expect that the difference between the two would be more likely to occur in the category of contact with others than the self awareness. However, this is not the case. So is self awareness best evaluated externally or internally? Do supervisors perform a function in highlighting the 'blind spots' for their supervisees and is their input, therefore, an essential tool in the development of self awareness?

Students in the second year of training are very much novice practitioners. Does the role of a supervisor change with experience? We do not have supervision data from the students in the fourth year of training, so cannot draw comparisons. Further research could look into comparing supervisors of students at different stages of training and experience.

Differences between the two groups show that students in the later stages of training demonstrate a higher degree of psychological health in both categories at least as perceived by themselves, further suggesting the link between training and psychological gains. In this type of project, that link could only be a suggestion, rather than a conclusion as the training itself includes a requirement for personal therapeutic work which should in itself make a difference. Further research, with a bigger sample and a wider range of measures could investigate whether there is a causal link between the two. It is hard, in any case, to know which elements of the training might have made the difference. We can only assume it is those aspects that call directly to the attributes identified in the measure. In order to research this conclusively, a control study could be used, but this would raise obvious questions of the ethics involved in deliberately withholding training that is assumed to be a vital part of developing an effective practitioner.

The 'Autonomy Questionnaire' is a new measure. This research further supports its structure and the separation of the two distinct categories of self awareness and ability for contact. Further research could validate and develop its use. Relationship between the categories of self awareness and contact with others could be investigated further in relation to attachment patterns.

Biljana van Rijn DPsych is a Teaching and Supervising Transactional Analyst (Psychotherapy) and the Head of Clinical Studies at Metanoia Institute. She can be contacted on Biljana.vanRijn@metanoia.ac.uk

Ciara Wild MSc Forensic Psychology is Researcher/ Clinic Administrator at Metanoia Institute.

Heather Fowlie is a Teaching and Supervising Transactional Analyst (Psychotherapy) and the Head of the Transactional Analysis Training Department at Metanoia Institute.
Charlotte Sills is a Teaching and Supervising Transactional Analyst (Psychotherapy) and a Visiting Professor at Middlesex University, working at Metanoia Institute and Ashridge Consulting, UK.

Servaas van Beekum is a Teaching and Supervising Transactional Analyst (Educational) and Director at the Australian Centre for Integrative Studies.

\section{References}

Allen, J. R., \& Allen, B. A. (1997). A New Type of Transactional Analysis and One Version of Script Work with Constructionist Sensibility. Transactional Analysis Journal, 27(2), 89-98.

Argyris, C., Putnam, R., \& Smith, D. (1987). Action Science: Concepts, Methods, and Skills for Research and Intervention. San Francisco: CA: Jossey-Bass.

Asay, T. P., \& Lambert, M. J. (1999). The Empirical Case for the Common Factors in Therapy: quantitative findings. In M. Hubble, B. Duncan, L. \& S. D. Miller (Eds.), The Heart and Soul of Change: What Works in Therapy (pp. 531-537). Washington, D.C: American Psychological Association.

Baldwin, S. A., Wampold, B. E., \& Imel, Z. E. (2007). Untangling the Alliance-Outcome Correlation: Exploring the Relative Importance of Therapist and Patient Variability in the Alliance. Journal of Consulting \& Clinical Psychology, 75(6), 842-852.

Berne, E. (1964). Games People Play: London: Penguin.

Berne, E. (1966). Principles of Group Treatment. New York: Oxford University Press.

Bordin, E. S. (1979). The Generalizability of the Psychoanalytic Concept of the Working Alliance. Psychotherapy: Theory, Research, Practice, 16(3), 252-260.

Cooper, M. (2008). Essential Research Findings in Counselling and Psychotherapy. The Facts are Friendly. Los Angeles: Sage Publications.

Gelso, C., J., \& Hayes, A. J. (2002). The Management of Countertransference. In J. C. Norcross (Ed.), Psychotherapy Relationships that Work: Therapist Contributions and Responsiveness to Patients (pp. 267-283): Oxford: Oxford University Press.

Goldfried, M. R., Castonguay, L. G., Hayes, A. M., Drozd, J. F., \& Shapiro, D. A. (1997). A Comparative Analysis of the Therapeutic Focus in Cognitive-Behavioral and Psychodynamic-Interpersonal Sessions. Journal of Consulting \& Clinical Psychology, 65(5), 740-748.

Hine, J. (1990). The Bilateral and Ongoing Nature of Games. Transactional Analysis Journal, 20(1), 28-39. 
Horvarth, A. O., \& Bedi, N. (2002). The Alliance. In J. C. Norcross (Ed.), Psychotherapy Relationships that Work:Therapist Contributions and Responsiveness to Patients 37-69. Oxford: Oxford University Press.

IARTA (2010) International Association for Relational Transactional Analysis http://www.relationalta.com/ 31.12.10

Lambert, M. J., \& Bergin, A. E. (1994). The Effectiveness of Psychotherapy. In A. E. Bergin \& S. L. Garfield (Eds.), Handbook of Psychotherapy and Behaviour Change (4 ed) 143-190 New Yortk: John Wiley.

Luborsky, L., McLellan, A. T., Woody, G. E., O'Brien, C. P., \& Auerbach, A. (1985). Therapist success and its determinants. Archives of general psychiatry, 42(6), 602-611.

Luborsky, L., Singer, B., \& Luborsky, L. (1975). Comparative Studies of Psychotherapies:Is it True that Everyone Has Won and All Must Have Prizes? Archives of General Psychiatry, 42(6), 602-611.
Smith, M. L., \& Glass, G. V. (1977). Meta-Analysis of Psychotherapy Outcome Studies. American Psychologist, 32(9), 752-760.

Tyrrell, C. L., Dozier, M., Teague, G. B., \& Fallot, R. D. (1999). Effective treatment relationships for persons with serious psychiatric disorders: the importance of attachment states of mind. Journal of Consulting \& Clinical Psychology, 67(5), 553-555.

van Beekum,. S., \& Krijgsman, B. (2000). From Autonomy to Contact. Transactional Analysis Journal, 30(1), 52-57.

van Rijn, B., Sills, C., Hunt, J., Shivanath, S., Gildebrand, K., \& Fowlie, H. (2008). Developing clinical effectiveness in psychotherapy training: Action research. Counselling and Psychotherapy Research, 8(4), 261-268.

Wampold, B. (2001). The Great Psychotherapy Debate Mahwah NJ: Lawrence Erlbaum Associates. 


\section{Taken at start/end of the training}

Categories in this questionnaire represent polarities of different qualities related to concepts of self awareness and contact with others. Please place yourself on the continuum of each category in relation to how you view yourself in your day to day life.

Name:

Date:

\begin{tabular}{|c|c|c|c|c|c|c|c|c|c|}
\hline A & 1 & Awareness of my internal dialogue & 1 & 2 & 3 & 4 & 5 & 6 & Lack of awareness of my internal dialogue \\
\hline A & 2 & Intuitive & 1 & 2 & 3 & 4 & 5 & 6 & Rigid \\
\hline A & 3 & Creating structure & 1 & 2 & 3 & 4 & 5 & 6 & Creating disorder \\
\hline A & 4 & Dealing with complexity & 1 & 2 & 3 & 4 & 5 & 6 & Need for simplicity \\
\hline B & 5 & Expressing feelings & 1 & 2 & 3 & 4 & 5 & 6 & Withholding feelings \\
\hline B & 6 & Expressing thinking & 1 & 2 & 3 & 4 & 5 & 6 & Keeping thoughts to myself \\
\hline B & 7 & Creating independence & 1 & 2 & 3 & 4 & 5 & 6 & Creating close bonds \\
\hline B & 8 & Creative rebellion & 1 & 2 & 3 & 4 & 5 & 6 & Adapting to authority \\
\hline A & 9 & Keeping an open mind & 1 & 2 & 3 & 4 & 5 & 6 & Making quick judgements \\
\hline B & 10 & Respectful & 1 & 2 & 3 & 4 & 5 & 6 & Critical of others \\
\hline B & 11 & Permissive & 1 & 2 & 3 & 4 & 5 & 6 & Firm \\
\hline B & 12 & Appreciative & 1 & 2 & 3 & 4 & 5 & 6 & Dismissive \\
\hline B & 13 & Making contact & 1 & 2 & 3 & 4 & 5 & 6 & Withdrawing \\
\hline B & 14 & Challenging authority & 1 & 2 & 3 & 4 & 5 & 6 & Complying \\
\hline A & 15 & Having one's own thoughts & 1 & 2 & 3 & 4 & 5 & 6 & Taking ideas from others \\
\hline A & 16 & Letting things happen & 1 & 2 & 3 & 4 & 5 & 6 & Maintaining Stability \\
\hline A & 17 & Active & 1 & 2 & 3 & 4 & 5 & 6 & Inactive \\
\hline A & 18 & Standing up for one's own needs & 1 & 2 & 3 & 4 & 5 & 6 & Prioritising the needs of others \\
\hline A & 19 & Letting go & 1 & 2 & 3 & 4 & 5 & 6 & Holding on \\
\hline
\end{tabular}

(c) Servaas van Beekum, 1996

Adapted by van Rijn, Sills, Fowlie, van Beekum, 2007 